\section{Noticias y comentarios}

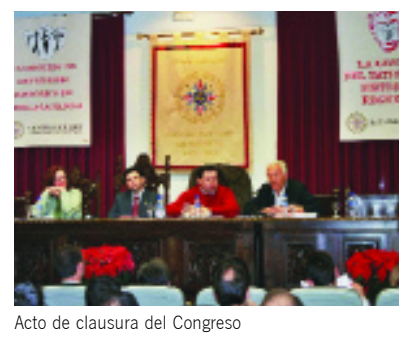

\title{
Castilla-La Mancha evalúa en un I Congreso la gestión institucional de su patrimonio histórico
}

La gestión del patrimonio histórico de la región castellano-manchega, analizada desde la doble perspectiva que supone el conocimiento de los fundamentos de la gestión institucional en los diversos campos de actuación patrimonial y algunos de los resultados más relevantes obtenidos como fruto de esa gestión, constituyó el eje vertebrador del I Congreso de Patrimonio Histórico de Castilla-La Mancha, organizado por el Centro Asociado de la UNED en Valdepeñas (Ciudad Real) del 16 al 18 de diciembre de 2004.

La jornada inaugural fue abierta por A. Caballero Klink, quien explicitó el esquema organizativo de la Dirección General de Patrimonio y Museos de la Junta de Comunidades de Castilla-La Mancha (JCCM) y sus correspondientes programas de actuación y criterios técnicos en cada uno de los ámbitos competenciales adscritos a esa unidad. Las dos siguientes intervenciones tuvieron su epicentro en el ámbito urbano, con la exposición de las directrices de gestión patrimonial desarrollada por el Consorcio de la Ciudad de Toledo y algunos de sus interesantes resultados (M. S. Sánchez-Chiquito) y un ilustrativo repaso a los modelos de Arqueología Urbana existentes en la región y su valoración dentro de la dialéctica entre "Ciudad" y "Patrimonio Arqueológico" (C. Fernández Ochoa).

El análisis de diferentes instrumentos legales y técnicos para la musealización y puesta en valor del patrimonio histórico fue iniciado por L. Abad Casal, que expuso los ejes directores del Plan de Parques Arqueológicos de Castilla-La Mancha valorando la normativa autonómica y su concreción en los cinco parques provinciales promovidos por la JCCM. Seguidamente se pasó revista a los logros y aplicaciones derivados de los programas de Escuelas-taller en relación con proyectos de intervención en yacimientos y monumentos históricos con especial atención a la actividad desarrollada en Alarcos, Ciudad Real (D. A. de Juan), y a los criterios rectores que se aplicaron en el proyecto del Parque Cultural de Nerpio (Albacete) cohesionado por la puesta en valor de una parte de su rico patrimonio de Arte Rupestre. Después de estas ponencias se procedió a la lectura de las comunicaciones centradas en los resultados de intervenciones desarrolladas al hilo de la realización de grandes obras públicas o privadas, intervenciones de consolidación y/o restauración de edificios, obras incluidas en la gestión regional, comarcal y municipal del patrimonio histórico, así como asuntos relacionados con la regulación de los colegios profesionales y el tratamiento del patrimonio en los diseños curriculares de la Enseñanza Secundaria.
La situación de los museos en Castilla La-Mancha, especialmente en relación al modelo de gestión autonómica y a la Ley regional de Museos que será promulgada en breve, fue abordada por R. Sanz Gamo. Una interesante reflexión sobre el concepto actual de "museo" y las necesidades reales demandadas por la sociedad multifacética en que vivimos fue propuesta por S. Palomero. Acompañaron esta sesión las comunicaciones centradas en las experiencias didácticas de algunos museos provinciales o los contenidos de instituciones museísticas de patrocinio local, así como muestras de los trabajos de restauración llevados a cabo en museos o la musealización de manifestaciones patrimoniales de diversa índole.

La jornada de cierre del Congreso se abrió con una Mesa Redonda en la que se hallaron representadas las instituciones y algunas de las profesiones relacionadas con la gestión del patrimonio histórico: técnicos representantes de la Administración autonómica, arqueólogos, restauradores, museólogos y profesores de Universidad. Entre los temas que generaron mayor discusión se encuentran los siguientes:

$>$ Marcos inter-administrativos de actuación en el patrimonio histórico. Situación actual de las relaciones entre las diversas instituciones con competencia en materia de patrimonio histórico

$>$ La normativa regional ¿Un encuadre legislativo suficiente?

> La multiplicación de museos locales y de promoción privada. Problemas de funcionamiento, organización y gestión

> Situación actual del ejercicio de las profesiones relacionadas con el patrimonio histórico

Aunque han sido muchos los asuntos tratados en este I Congreso de Patrimonio Histórico de Castilla-La Mancha, a modo de conclusión podríamos extraer algunos de las aspectos que, a nuestro juicio, parecen haberse reiterado en más ocasiones:

$>$ En el campo de las profesiones liberales implicadas en el tratamiento, conservación y estudio del patrimonio histórico se hizo hincapié en la situación actual de los restauradores, agravada por el importante indice de intrusismo profesional existente en este campo y por la falta de puestos de esta especialidad en la Administración regional. Se planteó la necesidad de crear plazas estables de restauradores en los Museos provinciales, en el cuadro técnico de la Dirección General de Patrimonio y Museos y en cada una de las Delegaciones Provinciales, así como de reforzar las Comisiones Provinciales del patrimonio histórico con un experto en esta materia. En cuanto a los arqueólogos, se advirtió la con- 
veniencia de disponer de un Colegio Profesional fuerte que regule la actividad y establezca un contacto fluido con la Administración regional. Desde el punto de vista de la Universidad se recordó una vez más la necesidad de adecuar el diseño curricular y la programación teórica de la especialidad al ejercicio profesional, con el fin de garantizar una sólida formación capaz de satisfacer las exigencias que la sociedad demanda hoy a los arqueólogos.

> Según se viene insistiendo desde numerosos ámbitos, debe desecharse el modelo de una "Arqueología de Gestión" disociada de una "Arqueología de Investigación". La Arqueología si no se orienta al estudio e interpretación histórica deja de ser Arqueología para convertirse en una mera actividad de concertación interadministrativa que únicamente garantiza el cumplimiento de la normativa sectorial en los ámbitos de afección al patrimonio histórico. En todo caso, cualquiera que sea el tipo de intervención por realizar, cada trabajo deberá obedecer a un proyecto técnico explícito y riguroso cuyos resultados serán objeto de evaluación administrativa. En el caso de las excavaciones sistemáticas programadas desde la Administración regional, el propio Director General de Patrimonio y Museos explicó su intención de que las distintas Universidades que trabajan en la región sean garantes de la validez científica de estos trabajos. Dentro también del ámbito de competencias de la Dirección General se halla la aprobación urgente de un Reglamento que organice, regule y clarifique la gestión institucional del patrimonio histórico, tarea que, según se indicó por parte de los responsables de la misma, está a punto de verse satisfactoriamente concluida. De igual modo se comentó la conveniencia de la puesta en marcha del Consejo de Patrimonio de CastillaLa Mancha, integrado por instituciones y expertos capaces de asesorar en cuestiones relacionadas con el patrimonio histórico regional.

$>$ En el terreno siempre complicado por los conflictos de intereses en que se desenvuelven la denominada "Arqueología Urbana" y la conservación de los Conjuntos Históricos, se reiteró la necesidad de generar proyectos integrales de investigación arqueológica cuya finalidad sea el conocimiento de la historia de la ciudad, tanto en su sentido vertical (tiempo) como horizontal (espacio), y cuyo objetivo no son los solares aislados, sino la ciudad en sí, concebida como un solo yacimiento, empleando palabras de C. Fernández Ochoa. Asimismo, desde la experiencia del ejercicio profesional de muchos de los participantes en el Congreso, se consideró repetidamente la necesidad de una articulación normativa en los planeamientos municipales sobre la protección del patrimonio histórico, como argumento para establecer las adecuadas medidas de control desde este ámbito competencial. En este sentido, se expusieron algunos ejemplos que ilustran los problemas derivados de esta gestión, en tanto que en otros casos, como Toledo, la existencia de un Consorcio que asesora, subvenciona y gestiona a los promotores particulares muchos de los aspectos referidos a la rehabilitación de sus inmuebles, minimiza el impacto de la normativa.

El balance de este I Congreso ha resultado, pues, altamente positivo, por lo que se alentó, por parte de las Instituciones y colectivos participantes, la continuidad de su convocatoria con carácter bie-nal. Por otra parte, la existencia de una serie de temas específicos sobre los cuales es conveniente intercambiar experiencias y conocimientos aconsejan la creación de unas Jornadas de Expertos que la UNED celebrará en la Sede Central con carácter anual. En este caso, se tratará de reuniones monográficas con una nómina de participantes cerrada en la que se debatirán algunos de los aspectos más conspicuos relacionados con el patrimonio histórico regional. Sólo resta ya esperar la próxima edición de las Actas, en la que ya estamos trabajando, y que contienen el desarrollo de todas las aportaciones arriba reseñadas, por lo que están Ilamadas a convertirse en el mejor testimonio de este fructífero encuentro.

Mar Zarzalejos Prieto

Luis Benitez de Lugo Enrich

Miguel Ángel García Valero

Comité Organizador

\footnotetext{
IV Premios Patrimonio de Periodismo 2005

> Convoca: Fundación del Patrimonio Histórico de Castilla y León.

> Objetivo: implicar a los medios de comunicación en la tarea de dar a conocer el Patrimonio Histórico de la

Comunidad y sensibilizar a la población sobre la necesidad de su conservación, restauración y promoción.

> Contenido: trabajos emitidos (radio, televisión e internet) o publicados (prensa) entre el 17 de mayo de 2004

y el 16 de mayo de 2005

> Presentación: hasta el 17 de mayo.

Más información:

Tel.: 983219700

Web: www.fundacionpatrimoniocyl.es

Correo-e.: fundacion@fundacionpatrimoniocyl.es
} 